\title{
Intranet Redesign and Change Management: Perspectives on Usability
}

\author{
Des Flanagan $^{\mathrm{a}}$ \\ Thomas Acton (corresponding author) ${ }^{\mathrm{a}}$ \\ Michael Campion $^{\mathrm{a}}$ \\ Seamus Hill ${ }^{\mathrm{a}}$ \\ Murray Scott ${ }^{\mathrm{a}}$ \\ ${ }^{a}$ J.E. Cairnes Graduate School of Business \& Public Policy, National University of Ireland, Galway, Ireland \\ E-mail: firstname.lastname@nuigalway.ie Tel: 353-91-493-806 Fax: 353-91-750-565
}

\begin{abstract}
As intranet implementations of enabling structures for internal electronic business communication increases, research is needed to provide an insight into the factors affecting a successful intranet design (Tang 2000). Using a case study involving a large multinational IT organisation, this paper studies changes made to the user interface design of a large multinational organisation's intranet and examines how that intranet's usability has been affected by these changes from both the managerial and employee end-user perspectives. The paper presents both a background on intranet design, its links to the design of web-based systems, and intranet-focussed usability issues.
\end{abstract}

Keywords: Intranet, Usability, Redesign, Change Management

\section{Introduction}

To maximise their potential, Intranets must not be allowed to evolve in an ad-hoc manner. Often, Intranet projects have been technology driven, being created for the sake of it (Tang 2000). An intra-organisational cross-departmental approach to intranet design and evolution opens up data resources, corporate processes, and knowledge applications to a wider base of users. As an organisation's Intranet evolves with changing goals and usage patterns, it starts to focus on knowledge creation as well as knowledge storage and access (Baker 2000). Behavioural and structural changes in organisational work patterns are necessary if this potential is to be maximised. Motivation to create, use and share information should be a primary, long-term critical success factor. Intranets are one mechanism enabling such knowledge creation and sharing.

However, management motivation and commitment to mechanisms facilitating knowledge creation and intra-organisational dissemination must be accompanied by employee 'user' buy-in. Intranet use should become part of employee daily routines, and should not constitute 'work' (Tang 2000). Effective usage is dependent upon intranet quality, strategic objectives and goals driving the usage, and alignment between the managerial aims and employee needs. Users must be given access to well-integrated well-designed information sources that are timely, up-to-date, maintainable and cost-effective. Intranets should provide fast and targeted access to relevant work- and organisational-related information so employees can stay focused on the connection between their work patterns and their company's strategic objectives. This promotes co-ordinated thinking and actions among employees, as well as maximising human resources (Denton 2003).

For an intranet to generate significant value-add, it must become the centrepiece of organisational strategy (Curry and Stancich 2000). In order to use an intranet as a strategic tool, management must take a strategic approach to designing, creating, maintaining and updating it. Companies aiming to gain competitive advantage from Intranet activities must realise that technological solutions alone are not sufficient. Competitive advantage will stem from the management of technology and effective use of resources (Gupta and Dale 1998).

This paper studies categorical changes made to the user interface design of a large multinational organisation's intranet and examine how that intranet's usability has been affected by these changes from both the managerial perspective, which focuses on the improvement of individual and workgroup performance, and employee 'end-user' perspectives. It is hypothesised that individual and categorical design changes to the intranet will either positively or negatively affect its usability. However, any such effects may be interpreted and regarded differently from management and end-user perspectives. The paper begins by outlining the attributes central to the usability of an intranet. Following this the research design is described in section 3. The findings are discussed in section 4 and finally the conclusion and possible future work are outlined in section 5 . 


\section{From Intranets to Usability}

Intranets are organisationally internal privately owned computing networks where access is only to authorised users. Intranet applications differ in many ways including; users, tasks, types of information, amount of information available (Nielsen 1997). Modern intranet design derives from implementations of Web-enabled technologies, encompassing and facilitating multiple websites and web pages, and providing organisational resources such as e-mail, newsgroups, and online meeting facilities (Baker 2000; Curry and Stancich 2000, Denton 2003). As intranet implementations of enabling structures for internal electronic business communication increases, research is needed to provide an insight into the factors affecting a successful intranet design (Tang 2000). However, as well as implementing a successful intranet design it is also important to be aware that very effective intranets are often not the result of design alone, but the continuous monitoring of user and business needs, and remaining aligned with current business strategies (Maurer and Calabria 2004).

Whether an Intranet has been implemented as an operational tool or as a strategic/tactical-level vehicle, it must be designed to be usable by employees. A number of attributes are central to the usability of an Intranet. The product should be useful, easy to learn, easy to use and consistent (Gould and Lewis 1985; Palmer 2002). Authors such as Lecerof and Paterno (1998) and Juristo et al. (2001) extend this list of attributes to also include memorability and productivity. Whilst intranets are closed systems, they are derivations of web-based structures: usability has been identified as a vitally important aspect of web-based systems (Juristo et al., 2001; Agarwal and Venkatesh, 2002; Lecerof and Paterno, 1998).

Usability is in itself an umbrella term encompassing many subcomponents: as such usability cannot be measured in a way that is consistent across studies examining the issue. However, usability is assessed through aggregated and sometimes selective measurements of these subcomponents (Nielsen and Levy 1994). There are differences in opinion regarding the particular components to use (Aladwani and Palvia 2002). Most authors include ease of use, 'learnability', number of errors made during tasks, and satisfaction as measures of usability (Nielsen 2001; Carroll et al. 2002; Juristo et al. 2001; Lecerof and Paterno 1998). Others extend this set to also include efficiency and emotion (Kim and Moon 1998; Agarwal and Venkatesh 2002; Lindgaard and Dudek 2002). Davis (1989) takes a different viewpoint, maintaining that there has been widespread use of invalidated measures in terms of design, selection, implementation and evaluation. Both Davis (1989) and Adams et al. (1992) regard successful usability including measures of perceived usefulness and perceived ease of use.

Perceived usefulness is the extent, to which a system will help people do their jobs. Perceived ease of use refers to the ease with which a user can use a system (Davis, 1989). Davis (1989) also shows that system usage is determined primarily by its perceived usefulness, and secondarily by its ease of use, and advises not to put emphasis on ease of use at the cost of functionality. Many authors comment that usability factors can be classified under subjective user preferences and objective performance measures (Nielsen and Levy 1994; Agarwal and Venkatesh 2002; Kissel 1995). In the past, focus has primarily been on objective measures, such as 'learnability', number of errors, and time needed to complete tasks. Today, companies investing in online technologies need to see the benefits of their investments, and to make this possible an appropriate tool for measuring the quality of their underlying systems must be identified (Aladwani and Palvia 2002).

In terms of an ideal user interface, Shneiderman et al. (1998) states that an interface should be comprehensible, predictable, and controllable. Colour should be applied both aesthetically and expressively, so it can be used as a communication tool and add to the information being presented (Alben et al., 1994; MacDonald, 1999). Navigation should be simplified through effective use of links, frames, text and buttons (Becker and Mottay, 2001). Agarwal and Venkatesh (2002) state that content is a critical feature affecting usability, with Zhang and von Dran (2002) concluding that customisation of content can increase the user experience. Catering for the diversity among end-users is a major challenge for interface developers, who must know how certain users differ and what special needs they have (Shneiderman and Hochheiser, 2001; Leventhal et al., 1994; Apple Computer Co., 1995; Huang, 2003).

\section{Research Method}

Using a case study involving a large multinational IT organisation, this research focuses on user interface changes made to the design of that organisation's worldwide intranet, analyses how that intranet's usability has been affected by these changes, and investigates the perceived effects of these changes on business processes and goals.

The 3-stage study involved a 'top-down' managerial-focussed qualitative method with a 'bottom-up' employee-based quantitative approach. For this study, interviews and in particular telephone interviews were the chosen qualitative methods for stages 1 and 2, while a quantitative web survey was adopted for stage 3 (see Table 1). The longitudinal aspect allowed the impact of design changes on the organisations intranet to be assessed over a three month period.

The first two stages were qualitative, involving interviews with the five managers within the organisation who drove the intranet design changes from the top-level. Prior to the implementation of any alterations to the existing intranet the 
first set of interviews gathered data on why the intranet design changes were being sought. The second set of interviews were conducted three months after the changes were introduced to explore whether the desired effects of the changes had been realised from a managerial perspective. The third stage utilised a web survey to gather the organisation's employee 'end-user' opinions on the design changes and a frequency distribution of the results was generated. This final stage occurred in parallel with stage 2. The purpose of each stage of the research is detailed below.

\subsection{Research Stage 1}

Stage 1 involved a series of structured interviews with the sample population of managers championing the changes to the Intranet in order to gain an understanding of the drivers for the intranet design changes and of this sample's initial satisfaction levels with the design changes. The central purpose of Stage 1 was to allow the researcher to gain an understanding of the rationale behind the design changes to the intranet.

In addition, Stage 1 was intended to gather data on possible usability improvements arising from the design changes from the point of view of those who drove the project.

\subsection{Research Stage 2}

Stage 2 was a similar series of structured interviews with the same sample of managers to determine each manager's evaluation of the design changes after a three month period had elapsed, and to compare this evaluation to the expectations that each manager had for the design changes when the first set of interviews were carried out in Stage 1. The central purpose of Stage 2 was to obtain data reflecting how the participants of Stage 1 perceived the intranet's design changes following a three month period for the organisation to become accustomed to the changes. The thoughts of the participants at this stage of the research were then compared to their expectations when Stage 1 was carried out.

The primary objective of carrying out interviews for Stage 1 and, at a later date, for Stage 2 was to allow the managers who were driving the Intranet changes to share their experiences on implementing the design changes and to give their opinions on the success of the changes after an elapsed period. This qualitative and interpretivist approach allowed the themes that arose from the interview questions in Stage 1 to form the basis for the interview questions for Stage 2 .

\subsection{Research Stage 3}

Stage 3 consisted of a web-based survey, completed by over 30 employees who were end-users of the intranet. The main purpose of stage 3 was to gather data from the end-users regarding their opinions on the usability of the intranet following the design changes and to compare employee viewpoints (as end-users) to management intentions and views.

A survey was the research approach chosen as its focus is on extracting data which allowed the researcher to understand the underlying principles driving the intranet changes. Past literature deems the survey approach suitable for gathering data on specific topics under study (Adams, 1992; Caldwell and Uang, 1995; Chau and Hu, 2002; Kwahk and Han, 2002; Gelderman, 1998). Also, reliable survey instruments such as structured interviews were well suited for this stage of research. The use of structured interviews for data collection helped address the primary and secondary objectives outlined above and to ensure valid and reliable results are gathered from this study, all participants chosen for the interview stages had adequate knowledge of the topics under study.

\section{Findings}

This research focuses on categorical changes made to the user interface design of the intranet of a large multinational organisation, specifically:

$\rightarrow$ Colour change of elements on the webpage;

$\vartheta$ Change in appearance of images;

? Change in design of horizontal navigation.

The research also examines how that intranet's usability has been affected by these changes both from the perspective of management and that of employee 'end-users' It investigates improvements in information retrieval as well as the issue of change management and the willingness of end-users to embrace the changes made to the intranet. The main findings are outlined below.

\subsection{Colour Usage}

All interviewees acknowledged that the change in colour scheme of a number of elements on the intranet were driven by the Global Branding Communications team within the organisation under study, to allow for consistency across not only the portal, but everything that comes out of the marketing side of the organisation. This includes a move to align and streamline the look and feel of the organisation. It also allows the organisation to communicate one brand to the customer, both internally and externally.

With regard to the portal, the goal of having a new visual identity was to transition the organization's brand elements 
from purely external-facing to internal-facing, thus uniting employees under one common identity. There was also expectation that a new visual identity would drive cost improvements across the entire corporation as too many people had been doing their own thing. This could be achieved by removing many of the inconsistencies about the intranet's look-and-feel, and everything that contributes to the brand identity.

An additional motive for changing the colour scheme was the Americans with Disabilities Act (A.D.A.) which details the types of changes that should be made to a website to make it more user-friendly for users that have disabilities of one sort or another, but typically visual impairment.

The colour change of a number of elements on the webpage was, to a large extent, a success in that the expectations associated with this design change were met. Consistency was promoted on the intranet through the colour change of both the background of the webpage and the horizontal navigation. This is consistent with findings from a study by Becker and Mottay (2001) who outline that consistency should relate to both the colour of the background of the webpage, and the colour of the links used throughout the website. The white background was found to tie-in well with the black horizontal navigation which may be because, as MacDonald (1999) points out, maximising the contrast between elements on the webpage improves look-and-feel and hence promotes consistency.

However, the colours used for the horizontal navigation were found to create confusion regarding what's highlighted and what's not. This may be due to the fact that the colours used in the horizontal navigation do not stand out as well as users would like. One possible solution may be to use colours which complement each other and hence minimise confusion as outlined by Ling and van Schaik (2002) who state that the navigation area should be given special attention, with attention-grabbing colour being placed here rather than the content area of the web page. A primary motive for changing the background colour of the webpage was to promote usability. The white background was found to provide the greatest readability to the user and to also care for people with visual impairment, which feels may be due to a high level of contrast on the webpage improving performance, as found in a study by MacDonald (1999).

The change in colour scheme of the banner at the top of the webpage was viewed as a limited success by participants who took part in this study. The decision to change the colour scheme from being one constant colour to rotating through a palette of colours on a daily basis was driven by the Global Branding Communications team within the organisation as the new company identity is tied in to an entire palette of colours and not just one in particular.

On the positive side, consistency across the intranet was improved as a result of the colour scheme changing on a daily basis. This may be due to the fact that appropriate use of colour can improve the effectiveness of graphical displays, as outlined by Ling and van Schaik (2002). This design change also influenced the usability of the intranet as the colour scheme used for the top banner accentuated familiarity among end-users for the intranet. This appears to illustrate that the consistent use of a complementary colour scheme, coupled with the use of quality graphic design, can help users to become familiar with an interface, as found in studies by Rosen and Purinton (2002) and Ling Ngo et al. (2003).

However, a number of important problems arose with this design change to the banner. For example, the rotating colour in the banner limits the range of colour that can be used elsewhere on the webpage, as there may be a clash with the colour being used in the banner on any given day. One explanation for these negative side-effects may be provided by Budgen (1995), who acknowledges the number of problems that may result from interface design changes, and concludes that the design team can face tricky situations, as addressing one problem to improve usability may open up other, more complicated problems.

\subsection{Imagery}

The change in the appearance of images used on the intranet, in terms of both image size and shape, was once again driven by the Global Branding Communications and it helped to promote consistency throughout the portal. It was also felt that the previous round-cornered images had been a design style of the organisation under study, and therefore a new cleaner style was required and that the rounded corners should be discarded. For this reason a crisp square-corner design was chosen. The image size was standardised to tie in with the overall new image design style.

Expectations regarding the change in image size and shape were met, with the square-shaped images of a standardised size promoting a consistent look-and-feel. No impact on usability was expected, nor was realised. The changes in the appearance of images may have had a positive effect on consistency because of the cleaner style with which the square-shaped images promoted. Nielsen and Sano (1994) state that consistent design techniques applied to graphic elements increases user satisfaction across an entire site.

\subsection{Navigation}

The primary motive in changing the navigation structure of the intranet from a drop-down menu to a two-level horizontal menu was to increase usability and assist users better in determining their current and previous locations on the intranet. This was only a minor success. Incorporating two horizontal levels of navigation reduced the number of users getting lost while browsing through the intranet, and hence contributed to improving productivity. This may be 
due to the improved efficiency experienced from deploying the new navigational system which, according to Palmer (2002), can make information easier to find and more relevant to the user. In turn, this can improve employee productivity, according to Nielsen (2001).

However, usability improvements emanating from the two-level horizontal navigation system were found to be compromised by having the links on the vertical or left navigation listed in alphabetical order. Usability training has shown that only long alphabetical lists are user-friendly. For short lists, like those used on the Intranet's vertical navigation, it's extremely important to put them in order of importance, or some kind of grouping that puts similar things together. This was found to hinder fast information retrieval which may be due to less important information being displayed on the webpage than if the links were listed in order of importance. A study carried out by Shneiderman and Chimera (1994) found that online browsing can be enhanced by interface designs that display appropriate information in appropriate places.

\subsection{Informational Retrieval}

In carrying out the design changes with the aim of implementing a "breadcrumb trail", the organisation under study had hoped to achieve faster information retrieval for users of the intranet. However, findings from this research indicate that this has not been a success. Although users have been provided with a visual clue of their navigational path, the visual clue has been found to be just another way of finding information on the intranet. Therefore it is felt that, contrary to a study carried out by Weinreich and Lamersdorf (2000), integrating the user's history into the navigation trail is not enough to improve information retrieval. What may be needed is a more consistent hierarchy across the intranet to allow users have an improved logical understanding of their whereabouts in the navigation structure. Palmer (2002) supports this, stating that navigation is influenced by the sequencing, layout, and arrangement of the website.

This research also found that accurate labelling of links facilitates faster information retrieval on an intranet. This may signify that accurate labels minimise confusion among users who become more knowledgeable on which links to follow and which to ignore. Weinreich and Lamersdorf (2000) and Kopetzky and Muhlhauser (1999) support this finding, stating that there results a cognitive overhead from the extra effort needed to follow several navigation trails at the one time. This dilemma has long been associated with users wondering whether they should follow a link or not, and could be reduced by an improvement in link capabilities or by providing an overview of the hyperspace.

Incorporating customisable features into the interface design can also enhance information retrieval on an intranet, as this research has found. When carrying out the design changes to the intranet under study, the personalisation of links which had existed on the previous design was eliminated, and this was found to have had a detrimental effect on information retrieval. The results from this research support Curry and Stancich (2000) in stating that this may be due to the apathy among users for mass communication, when instead, according to Perrott (2001), information on an intranet should be targeted at employees, and interactive features added.

\subsection{Change Management}

Change management was found to be a factor in limiting the success of the intranet design changes. Caused by the dislike among employees for change, users had to grow to accept the change to the horizontal navigation, rather than embrace it. This may have been due to inadequate communication from top management regarding the changes in employee behaviour that were needed in order to make the two-level horizontal navigation structure a greater success. This is consistent with findings from a study by Curry and Stancich (2000) who state that, when redesigning an Intranet, behavioural and structural changes in the organisation's work patterns will be needed in order to maximise its potential. Top-down commitment, according to Tang (2000), must be accompanied by bottom-up employee buy-in.

\section{Conclusions}

This research studied the design changes made to an organization's intranet, and analysed how the intranet's usability was subsequently affected. The colour change of a number of elements on the webpage was, to a large extent, a success in that the expectations associated with this design change were met. Consistency was promoted on the intranet through the colour change of both the background of the webpage and the horizontal navigation. However, the colours used for the horizontal navigation were found to create confusion regarding what was highlighted. A primary motive for changing the background colour of the webpage was to promote usability. The change in colour scheme of the banner at the top of the webpage was viewed as a limited success by participants who took part in this study.

Expectations regarding the change in image size and shape were met, with the square-shaped images of a standardised size promoting a consistent look-and-feel. No impact on usability was expected, nor was realised. The primary motive in changing the navigation structure of the intranet from a drop-down menu to a two-level horizontal menu was to increase usability. and was only a minor success. However, usability improvements emanating from the two-level horizontal navigation system were found to be compromised by having the links on the vertical or left navigation listed in alphabetical order. This was found to hinder fast information retrieval which may be due to less important information being displayed on the webpage than if the links were listed in order of importance. 
Results also indicate that accurate labelling of links facilitates faster information retrieval on an intranet, and that information retrieval on an intranet can also be enhanced by incorporating customizable features into the interface design. When carrying out the design changes to the intranet under study, the personalisation of links which had existed on the previous intranet design was eliminated, and this was found to have had a detrimental effect on information retrieval. Finally, change management was found to be a factor in limiting the success of the intranet design changes. Caused by the dislike among employees for change, users had to grow to accept the change to the horizontal navigation, rather than embrace it. This may have been due to inadequate communication from top management regarding the changes in employee behaviour that were needed in order to make the two-level horizontal navigation structure a greater success.

The purpose of this research was to study categorical changes made to the user interface design of the intranet of a large multinational organisation and examine how that intranet's usability had been affected by these changes from both the managerial and employee 'end-user' perspectives. The overall findings indicate that although the redesigning of the user interface was largely successful, the degree of success was to a large extent based upon the management of the changes which was found to be a factor in the successful implementation of the intranet redesign.

Future work extending from this research includes examining whether the difficulties encountered by users in deciding whether to follow a link or not could be reduced by an improvement in link capabilities or by providing an overview of the hyperspace; analysis of interface designs that display information in appropriate places to provide enhanced online browsing; and further study on employee targeting of intranet information.

\section{References}

Adams, D. A., Nelson, R. R. and Todd, P. A. (1992) Perceived usefulness, ease of use, and usage of information technology: A replication, MIS Quarterly, 16 (2), pp. 227-248.

Aladwani, A. M. and Palvia, P.C. (2002) Developing and Validating an Instrument for Measuring User-Perceived Web Quality, Information and Management, 39, pp. 467-476.

Alben, L., Faris, J. and Saddler, H. (1994) Making it Macintosh: designing the message when the message is design, Interactions, 1 (1), pp. 11-20.

Agarwal, R. and Venkatesh, V. (2002) Assessing a Firm's Web Presence: A Heuristic Evaluation Procedure for the Measurement of Usability, Information Systems Research, 13 (2), pp. 168-187.

Apple Computer Co. (1995) Macintosh Human Interface Guidelines.

Baker, S. (2000) Getting the most from your Intranet and extranet strategies, Journal of Business Strategy, 21, p. 40.

Becker, S. A. and Mottay, F. E. (2001) A global perspective on website usability, IEEE Software, pp. 54-61.

Budgen, D. (1995) Design Models from Software Design Methods, Design Studies, 16, pp. 293-325.

Caldwell, B. S. and Uang, S. T. (1995) Technology Usability and Utility Issues in a State Government Voice Mail Evaluation Survey, Human Factors, 37 (2), pp. 306-320.

Carroll, C., Marsden, P., Soden, P., Naylor, E., New, J. and Dornan, T. (2002) Involving users in the design and usability evaluation of a clinical decision support system, Computer Methods and Programs in Biomedicine, 69 (2), pp. 123-135.

Chau, P. Y. K. and Hu, P. J. (2002) Examining a Model of Information Technology Acceptance by Individual Professionals: An Exploratory Study, Journal of Management Information Systems, 18 (4), pp. 191-230.

Curry, A. and Stancich, L. (2000) The intranet - an intrinsic component of strategic information management, International Journal of Information Management, 20, pp. 249.

Davis, F. D. (1989) Perceived Usefulness, Perceived Ease of Use, and User Acceptance of Information Technology, MIS Quarterly, September, pp. 318-340.

Denton, D. K. (2003) Use an Intranet for Performance Measurement., Industrial Management, 45, p. 28.

Gelderman, M. (1998) The relation between user satisfaction, usage of information systems and performance, Information \& Management, 34 (1), pp. 11-18.

Gould, J. and Lewis, C. (1985) Designing for usability: Key principles and what Designers think, Communications of the ACM, 28(4), pp. 300-311.

Gupta, A. S. and Dale O. (1998) Managing computing resources in intranets: an electronic commerce perspective., Decision Support Systems, 24, pp. 55.

Huang, A. H. (2003) An Empirical Study of Corporate Web Site Usability, Human Systems Management, 22, pp. 23-36.

Juristo, N., Windl, H. and Constantine, L. (2001) Introducing usability, IEEE Software, 18 (1), pp. 20-21. 
Kim, J. and Moon, J.-Y. (1998) Designing towards emotional usability in customer interfaces-trustworthiness of cyber-banking system interfaces, Interacting with Computers, 10 (1), pp. 1-29.

Kissel, G. V. (1995) The effect of computer experience on subjective and objective software usability measures, Conference on Human Factors and Computing Systems, Denver, CO USA, May 7 - 11, pp. 284-285.

Kopetzky, T. and Muhlhauser, M. (1999) Visual preview for link traversal on the World Wide Web, Computer Networks, 31 (11-16), pp. 1525-1532.

Kwahk, J. and Han, S. H. (2002) A methodology for evaluating the usability of audiovisual consumer electronic products, Applied Ergonomics, 33 (5), pp. 419-431.

Lecerof, A. and Paterno, F. (1998) Automatic support for usability evaluation, IEEE Transactions on Software Engineering, 24 (10), pp. 863-888.

Leventhal, L., Teasley, B. and Stone, D. (1994) Designing for diverse users: will just a better interface do?, Proceedings of the CHI '94 conference companion on Human factors in computing systems, Boston, USA, April 24 - 28, 1994, Boston United States, pp. 191-192.

Lindgaard, G. and Dudek, C. (2002) What is this evasive beast we call user satisfaction?, Interacting with Computers, 15, pp. 429-452.

Ling, J. and van Schaik, P. (2002) The effect of text and background colour on visual search of Web pages, Displays, 23 (5), pp. 223-230.

Ling Ngo, D. C., Teo, L. S. and Byrne, J. G. (2003) Modelling interface aesthetics, Information Sciences, 152 25-46.

Maurer D. and Calabria T. (2004) 10 Ways to continuously improve your intranet, [Online], http://www.steptwo.com.au/papers/kmc_continuousimprovement/pdf/KMC_ContinuousImprovement.pdf

MacDonald, L. W. (1999) Using color effectively in computer graphics, Computer Graphics and Applications, IEEE, 19 (4), pp. 20-35.

Nielson, J. (1997) The Difference Between Intranet and Internet Design, [Online], useit.com, available at http://www.useit.com/alertbox/9709b.html

Nielsen, J. (2001) Novice vs. Expert Users, Vol. 2001, [Online], useit.com, available at http://www.useit.com/alertbox/20000206.html

Nielsen, J. and Levy, J. (1994) Measuring usability: Preference vs. Performance, Communications of the ACM, 37 (4), pp. 66-76.

Nielsen, J. and Sano, D. (1994) Design of SunWeb - Sun Microsystems' Intranet, [Online], useit.com http://www.useit.com/papers/sunweb/

Palmer, J. W. (2002) Web Site Usability, Design, and Performance Metrics, Information Research, 13 (2), pp. 151-167.

Perrott, N. (2001) Intranets: Considering the User Experience, Strategic Communication Management, 5, pp. 32.

Rosen, D. E. and Purinton, E. (2002) Website Design: Viewing the Web as a Cognitive Landscape, Journal of Business Research, pp. 1-8.

Shneiderman, B. and Hochheiser, H. (2001) Universal usability as a stimulus to advanced interface design, Behaviour \& Information Technology, 20, pp. 367-376.

Shneiderman, B., Byrd, D. and Croft, W. B. (1998) Sorting out searching: a user-interface framework for text searches, Communications of the ACM, 41 (4), pp. 95 - 98.

Shneiderman, B. and Chimera, R. (1994) An exploratory evaluation of three interfaces for browsing large hierarchical tables of contents, ACM Transactions on Information Systems, 12 (4), pp. 383-406.

Tang, S. M. (2000) An impact factor model of Intranet adoption: an exploratory and empirical research., Journal of Systems \& Software, 51, p. 157.

Weinreich, H. and Lamersdorf, W. (2000) Concepts for improved visualization of Web link attributes, Computer Networks, 33 (1-6), pp. 403-416.

Zhang, P. and von Dran, G. M. (2002) User Expectations and Rankings of Quality Factors in Different Web Site Domains, International Journal of Electronic Commerce, 6 (2), pp. 9-33. 
Table 1. Research Stages

\begin{tabular}{|l|l|l|l|l|}
\hline Stage & $\begin{array}{l}\text { Research } \\
\text { Approach }\end{array}$ & Method & Source & Research Focus \\
\hline 1 & Qualitative & $\begin{array}{l}\text { Individual } \\
\text { Interview }\end{array}$ & Managers & $\begin{array}{l}\text { Rationale for the intranet design changes; } \\
\text { potential usability improvements from } \\
\text { the proposed changes }\end{array}$ \\
\hline 2 & Qualitative & $\begin{array}{l}\text { Individual } \\
\text { Interview }\end{array}$ & Managers & $\begin{array}{l}\text { Extent to which desired effects had been } \\
\text { realised }\end{array}$ \\
\hline 3 & Quantitative & $\begin{array}{l}\text { Web-based } \\
\text { survey }\end{array}$ & $\begin{array}{l}\text { Intranet } \\
\text { end-users }\end{array}$ & $\begin{array}{l}\text { End-user opinions of the usability of the } \\
\text { Intranet after the design changes }\end{array}$ \\
\hline
\end{tabular}

